\title{
Mood, mileage and the menstrual cycle
}

\author{
I. M. Cockerill MEd PhD, A. M. Nevill BSc PhD and N. C. Byrne BA \\ School of Sport and Exercise Sciences, University of Birmingham
}

Forty women took part in a study to determine the effects of high-intensity training and the menstrual cycle on mood states. Half of the sample were competitive distance runners following a training load of between $50 \mathrm{~km}$ and $130 \mathrm{~km}$ running per week. Seven athletes were amenorrhoeic and 13 either eumenorrhoeic or oligomenorrhoeic. The remaining 20 subjects were inactive women who menstruated regularly. The mean age of all 40 subjects was 29 years. Each subject completed two identical Profile of Mood States (POMS) questionnaires. The 33 menstruating subjects completed both a premenstrual and a midcycle form and the amenorrhoeic athletes completed the questionnaires at a 3-week interval, which acted as a control for the potential effects of premenstrual syndrome (PMS) among the menstruating females. Results showed highly significant differences in mood profiles among amenorrhoeic athletes, non-amenorrhoeic athletes and inactive women. The greatest difference was between premenstrual and midcycle measures for the inactive group. PMS appears to cause marked negative mood swings among menstruating women which the POMS inventory is sensitive in detecting. While the lowerintensity-training runners appeared to benefit psychologically from a training distance of approximately $50 \mathrm{~km}$ week $^{-1}$, high-intensity training had an adverse effect on mood.

Keywords: Mood, running, menstrual cycle

A principal development from the recent increase in sports participation among women has been an advance in research into the effects of strenuous exercise on the reproductive system ${ }^{1,2}$. It is well established that mood changes, that is to say transitory emotional states, occur among a high proportion of women during the few days before menstruation. These, and associated physical symptoms, combine to form what is known as the premenstrual syndrome (PMS) and the benefits of exercise as a means of alleviating PMS have received attention from researchers over a number of years ${ }^{3-8}$.

Research into the effects of exercise on mood has generally found that regular, intensive exercise, especially running, causes mood modification ${ }^{9-14}$. Exercise is usually shown to be beneficial in terms of reducing tension and increasing overall psychological well-being, although committed, or so-called

Address for correspondence: I. M. Cockerill, School of Sport and Exercise Sciences, University of Birmingham, PO Box 363, Edgbaston, Birmingham B15 2TT, UK

(C) 1992 Butterworth-Heinemann Ltd 0306-3674/92/030145-06 'addicted', runners may not derive similar psychological benefits from such activity. In addition, chronic high-intensity exercisers are frequently affected by disturbance to hormone balance which may produce athletic amenorrhoea (intermenses of more than 90 days), or oligomenorrhoea (irregular menstrual periods of 40-90 days' interval) ${ }^{1,15}$.

Where studies have failed to support the benefits of exercise for the generation of positive mood states, this has usually reflected poor control in the nature, extent, and intensity of exercise undertaken. In general, aerobic exercise, interspersed with short periods of anaerobic work taken for approximately $30 \mathrm{~min}$ each day, has been found to engender a positive mood. For example, Dyer and Crouch ${ }^{16}$ showed that vigorous, but not exhaustive, exercise assisted in coping with stress and was moodenhancing. However, in such studies it is important to determine whether subjects have negative moods before the commencement of exercise therapy; otherwise research showing that runners are usually less tense or depressed than non-runners may be because tense and depressed individuals are less likely to run than those who are not.

Among women, the effects of exercise on mood is likely to be compounded by the effects of exercise on the menstrual cycle. Although the precise mechanisms of athletic amenorrhoea are not yet fully understood ${ }^{1,17}$, menstrual irregularities have been found to occur more frequently among athletes than among the general population. Carlberg et al. ${ }^{18}$, for example, found an incidence of amenorrhoea in up to $51 \%$ of athletes, whereas it was not more than $5 \%$ among non-athletes.

It can be stated with some confidence that there is a positive correlation between training load and the incidence of athletic amenorrhoea ${ }^{19,20}$, although it has been suggested that there is a threshold of about $50 \mathrm{~km}$ running per week, beyond which no further increases in the severity of amenorrhoea occur ${ }^{21,22}$. It does appear, however, that the onset of amenorrhoea is associated with the percentage of aerobic capacity at which runners train rather than as a function of training load, per se, in terms of distance run ${ }^{23,24}$.

Having considered the effects of exercise on the menstrual cycle and on mood, the menstrual cyclemood relationship also requires examination. The responses of athletes to the physical stresses of training and competition are reflected in changes in bodily function. Such stresses are also mirrored in emotional behaviour, influencing hypothalamic function and causing an alteration in menstrual function ${ }^{25}$. 
Moreover, it has been proposed by Schwartz et al. ${ }^{27}$ that the onset of athletic amenorrhoea is associated closely with psychological stress as well as with intensive training. Severe emotional disturbance, or negative mood thus plays a major role in menstrual dysfunction. Ferstle ${ }^{27}$ has suggested that psychological trauma, intensive training and rapid weight loss are each important contributors to amenorrhoea in athletes. PMS is therefore considered to be the outcome of several factors, both physical and psychological, and the condition has been described as 'the recurrent somatic or psychic symptoms which may occur in relation to menstruation ${ }^{\prime 3}$.

From the evidence reviewed, three hypotheses were proposed:

1. Regular and committed women runners possess different mood profiles from inactive women.

2. Amenorrhoeic runners possess different mood profiles from non-amenorrhoeic runners.

3. Among both runners and inactive women, the premenstrual mood profile differs from the midcycle profile.

\section{Method}

\section{Subjects}

The study included 40 women subjects, 20 of whom were runners. Each runner was a regular, competitive, middle-distance or distance athlete of national standard. Subjects were members of the International Athletes' Club, London Road-Runners' Club and other athletic clubs in the UK. All athletes trained daily and a self-report questionnaire revealed that seven were amenorrhoeic, running $50-120 \mathrm{~km}$ week $^{-1}$, with an average of $84 \mathrm{~km}$ week ${ }^{-1}$. The remaining 13 were non-amenorrhoeic and ran between $50 \mathrm{~km}$ and $130 \mathrm{~km}^{\text {week }}{ }^{-1}$ with an average of $64 \mathrm{~km}$. A second group of 20 subjects was described as inactive - they reported that they did not participate in any physical activity additional to their normal occupations. All members of this group menstruated regularly and normally, and none used an oral contraceptive. The mean age of the 40 subjects was 29 years.

The Profile of Mood States (POMS) questionnaire ${ }^{28}$ was used to evaluate subjects' moods. POMS is a 65-item adjective checklist-type questionnaire, with responses made on a five-point scale to six mood factors: tension; depression; anger; vigour; fatigue; confusion. The POMS has been used extensively to investigate the moods of various sporting groups and of athletes of varying standards. Although Morgan ${ }^{29}$ described POMS as being the most predictive psychological tool that he had used with athletes, his studies have principally been of a descriptive rather than a predictive nature. As a predictor of performance in sport, POMS has been used specifically only in the recent study by Cockerill et al. ${ }^{30}$. However, Morgan was instrumental in devising the term 'iceberg profile' to describe the positive mood profile that he considered to be an attribute of the elite athlete - the so-called 'winner's profile'.
All subjects were required to complete two POMS questionnaires before going to bed and at least $2 \mathrm{~h}$ after training, since it has been shown by Mackenberg et al. ${ }^{31}$, Horne and Ostberg ${ }^{32}$, and Thayer ${ }^{33}$, that performance on a cognitive task varies according to the time of day. Although questionnaire completion was not considered to include a major cognitive component, it was deemed important to require all subjects to perform the task at a similar time of day in order to control for the morning-evening effect. Horne and Ostberg ${ }^{32}$ have stimulated interest in this effect with the publication of their questionnaire, which tends to show that morning and evening types manifest different levels of energetic arousal according to their classification by the questionnaire. Of the subjects 33 completed one questionnaire within the 5 days before the onset of menstruation and the second 14 days after the cessation of menstruation. The seven amenorrhoeic subjects were also asked to complete the two forms at a 21-day interval. This would enable the presence of an order, or time, effect on mood states to be detected and, in addition, would provide a benchmark or control for any changes in mood of the two menstruating groups over their normal cycle.

The data were analysed on the University of Birmingham's IBM 3090 mainframe computer and the BMDP $^{34}$ statistical software was used in the analysis. Specifically, the Total Mood Disturbance (TMD) scores were analysed using repeated measures analysis of variance (ANOVA) with the program BMDP2V, and the six mood profiles were analysed simultaneously using multivariate analysis of variance (MANOVA) with the program BMDP4V.

\section{Results}

The six mood factors of tension, depression, anger, vigour, fatigue, and confusion were the dependent variables. These six mood states can be combined by deducting the vigour score from the sum of scores for the other five mood factors to produce an overall measure of mood, described as Total Mood Disturbance (TMD) ${ }^{1}$. The TMD scores were analysed using repeated measures ANOVA with one between-group factor (amenorrhoeic runners, non-amenorrhoeic runners and inactive subjects) and one within-subject factor (the menstrual cycle phase). The mean TMD scores are given in Table 1.

A significant difference in TMD was found between the subject groups $(F=3.65$, d.f. $=2,37 ; P<$ $0.05)$. This was due mainly to the low TMD score of the non-amenorrhoeic runners. The overall effect of the menstrual cycle was found to be highly significant $(F=43.43$, d.f. $=1,37 ; P<0.001)$, caused by the greatly elevated premenstrual overall mean TMD score, 54.05, compared with the midcycle TMD score of 15.15. However, this pattern was not true for all three groups as shown in Figure 1, and exemplified by the highly significant group-by-cycle interaction $(F=$ 17.87 , d.f. $=2,37 ; P<0.001$ ).

The TMD scores give a useful overall measure of each subject's mood state, although there are several ways in which a similar TMD score can be obtained. 
Table 1. TMD scores for all three groups at both premenstrual and the midcycle phases

\begin{tabular}{lcccc}
\hline & Amenorrhoeic $(n=7)$ & Non-amenorrhoeic $(n=13)$ & Sedentary $(n=20)$ & Overall mean $(n=40)$ \\
\hline Premenstrual & 40.71 & 33.62 & 72.00 & 54.05 \\
Midcycle & 44.29 & 4.00 & 12.20 & 15.15 \\
Overall mean & 42.50 & 18.81 & 42.10 & 34.60 \\
\hline
\end{tabular}

Table 2. Correlation matrices for a premenstrual mood-state measures and $b$ for midcycle mood-state measures

\begin{tabular}{lrrrr}
\hline & Tension & Depression & Anger & Vigour \\
\hline a & & & & \\
$\quad$ Depression & 0.856 & & & \\
Anger & 0.756 & 0.720 & -0.398 & \\
Vigour & -0.444 & -0.391 & 0.528 & -0.417 \\
$\quad$ Fatigue & 0.658 & 0.598 & 0.564 & -0.439 \\
Confusion & 0.790 & 0.827 & & \\
b & & & & \\
Depression & 0.805 & 0.787 & -0.226 & \\
Anger & 0.662 & -0.400 & 0.584 & -0.453 \\
Vigour & -0.376 & 0.740 & 0.607 & -0.351 \\
$\quad$ Fatigue & 0.608 & 0.791 & & 0.477 \\
$\quad$ Confusion & 0.797 & & & \\
\hline
\end{tabular}

A more detailed analysis of the six individual mood factors is required because many differing mood profiles can produce an identical TMD score. But the six mood factors were found to be highly correlated at the premenstrual and midcycle stages of the menstrual cycle Table $2 a, b$, so discrete analysis of these six dependent variables would be inappropriate.

A second and more comprehensive procedure for interpreting the data was to compare subjects' mood profiles using multivariate analysis. The experimental design remained the same - the results of the six POMS factors were obtained from a two-factor experiment with repeated measures on one factor but the scores for each of the six factors were analysed as multiple dependent variables using MANOVA.

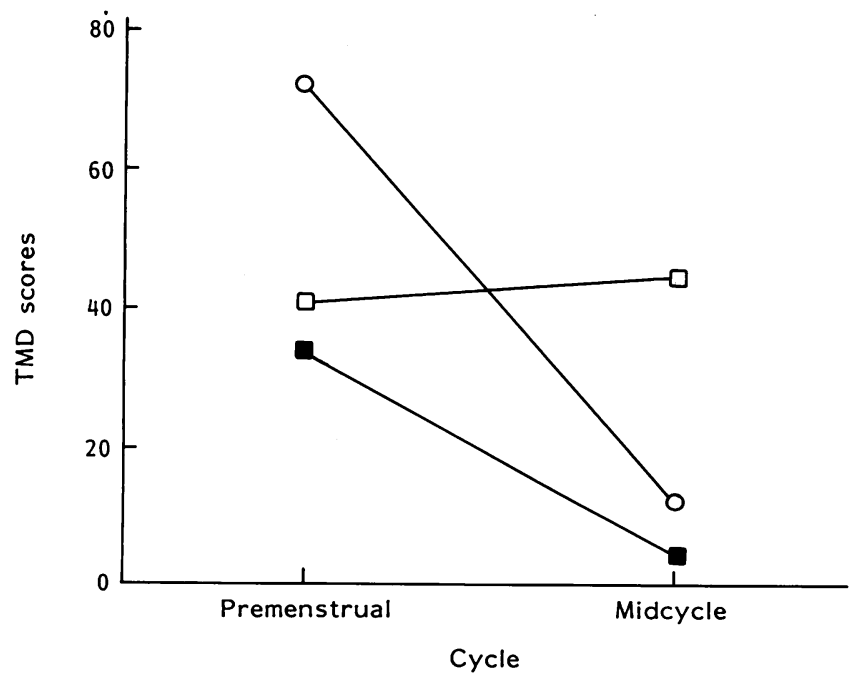

Figure 1. TMD scores for all three groups at the premenstrual and midcycle phases: $\square$, amenorrhoeic; non-amenorrhoeic; $O$, inactive
The mood profiles for both groups of runners and the sedentary group were found to vary significantly (Wilks' likelihood ratio, $L_{\mathrm{RATIO}}=0.5058$, d.f. $=12,64$; $P<0.05)$ as shown in Figure 2 . When individual mood factors were examined, the differences between the three profiles were found to be attributed primarily to significantly lower tension (7.2) and anger (6.4) scores for the non-amenorrhoeic runners when compared with the amenorrhoeic runners' (tension 11.4, anger 12.3) scores and the inactive subjects' (tension 12.6, anger 9.5) scores. In line with group TMD scores, the overall non-amenorrhoeic runners' mood profile displays a much more clearly identifiable iceberg shape than do the overall profiles of the amenorrhoeic runners and the inactive subjects.

The overall premenstrual and midcycle mood

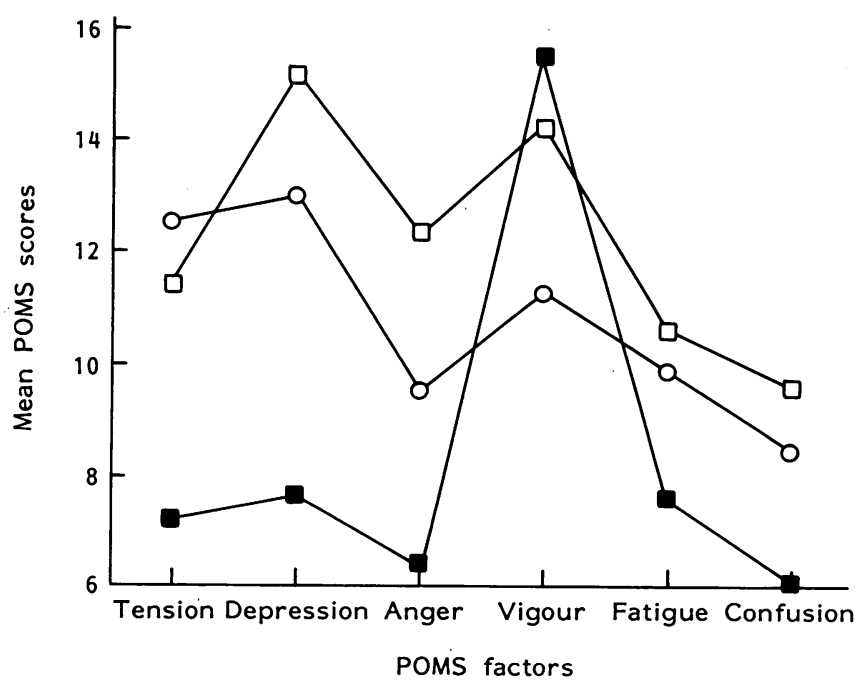

Figure 2. Overall mood profiles for all three groups: $\square$, amenorrhoeic; $\square$, non-amenorrhoeic; $O$, inactive 


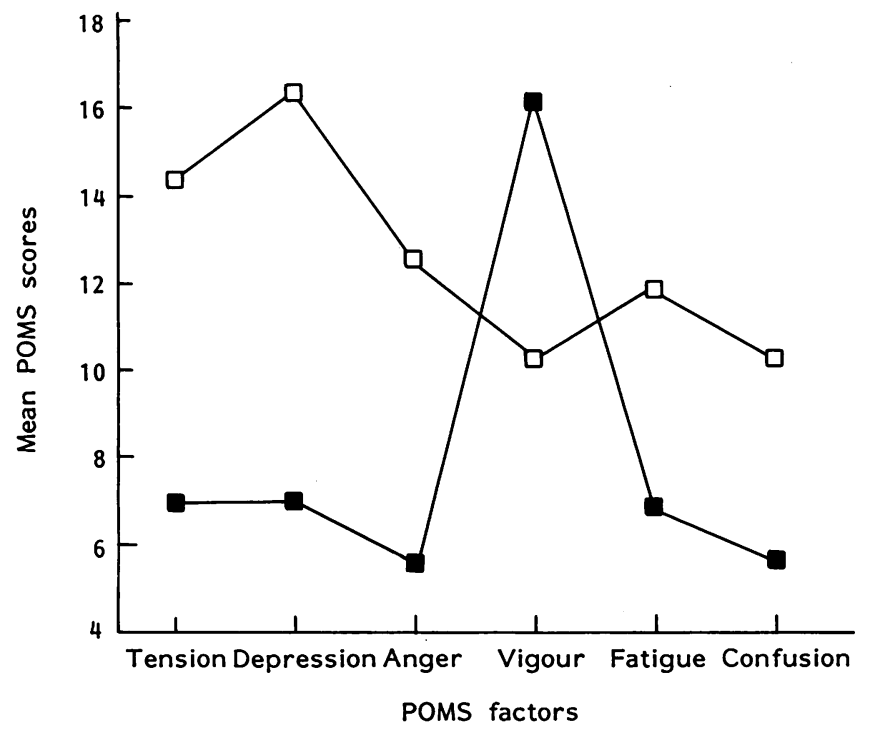

Figure 3. Premenstrual, $\square$, and midcycle, $\square$, mood profiles for all $\mathbf{4 0}$ subjects

profiles were also shown to vary significantly (Hotelling's $T$-squared, $T^{2}=72.52$, d.f. $=6,32 ; P<$ 0.001 ) as seen in Figure 3. Indeed, when all six individual mood factors were compared separately, highly significant differences occurred between the premenstrual and midcycle mood states for each factor. Figure 3 reveals that these were caused by the elevated premenstrual mood scores for: tension, 14.3; depression, 16.3; anger, 12.5; fatigue, 11.8; and confusion 10.2; together with a low score for vigour of 10.2. This contrasts with much lower midcycle mood state scores for: tension, 6.9; depression, 7.0; anger, 5.5; fatigue, 6.8; and confusion, 5.6; together with a higher vigour score of 16.1 .

The group-by-cycle profile interaction was also found to be highly significant (Wilks' likelihood ratio $L_{\mathrm{RATIO}}=0.3685$, d.f. $=12,64 ; P<0.001$ ), indicating that differences between the premenstrual and midcycle profiles were not common to all three groups, as illustrated in Figures $4 a-c$.

Figure 4 illustrates clearly the marked effects of the menstrual cycle on subjects' mood. When the two POMS test scores for the amenorrhoeic groups were compared in Figure $4 a$, the difference between scores over the 3-week interval was not significant. Thus, the mood of the group was shown to be consistent over this time span. However, clear differences in mood were observed in Figures $4 b$ and $c$ between the premenstrual and the midcycle stages for all 33 menstruating subjects. In particular, Figure $4 c$ provides a dramatic illustration of the marked differences between premenstrual and midcycle moods of the sedentary subjects.

\section{Discussion}

Highly significant differences in mood profiles were found between runners and inactive women and between the premenstrual and the midcycle testing sessions. Thus, the experimental hypothesis that exercise and the menstrual cycle have an effect on mood states was upheld. However, when allocating the runners to two separate groups according to
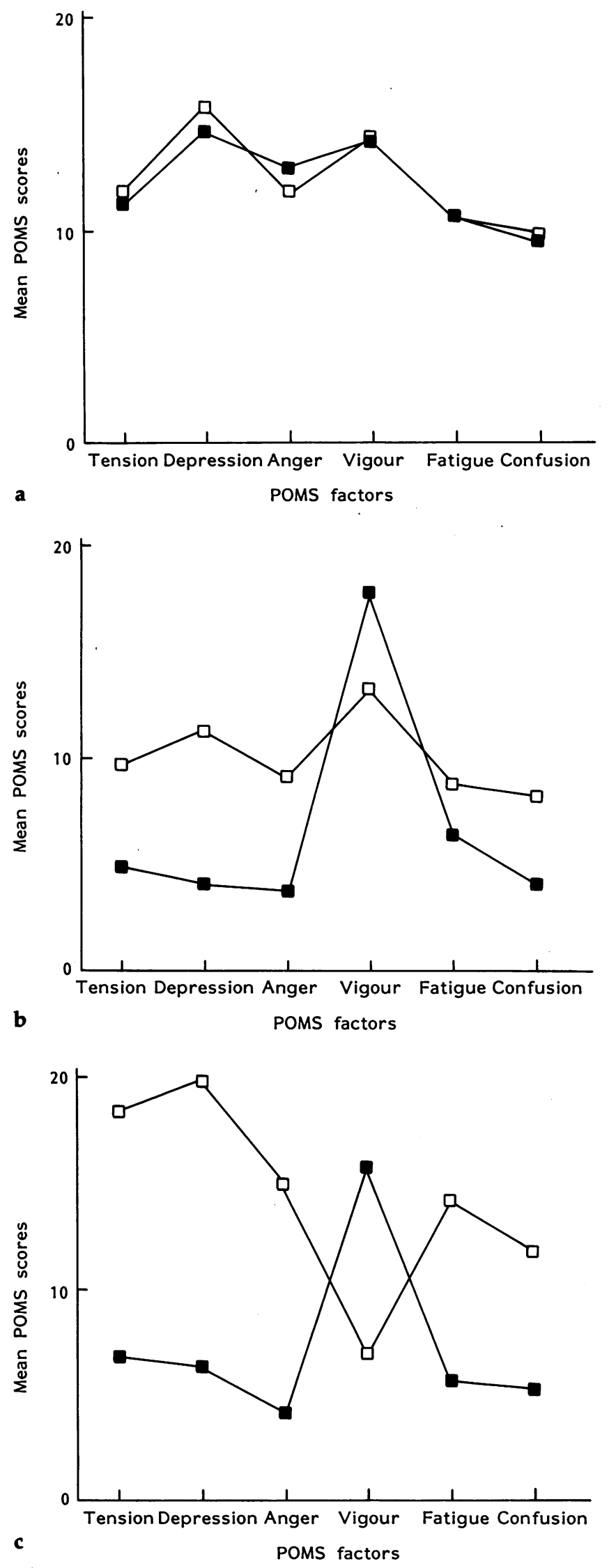

Figure 4. a Premenstrual, $\square$, and midcycle, $\square$, mood profiles of the amenorrhoeic runners ( $n=7)$; b premenstrual, $\square$, and midcycle, $\square$, mood profiles of the non-amenorrhoeic runners $(n=13)$; c premenstrual, $\square$, and midcycle, $\square$, mood profiles of the inactive subjects $(n$ $=20$ ) 
menstrual status, overall differences in mood were found to be influenced by the menstrual cycle, the extent of exercise, or both. For example, when all subjects were partitioned according to the POMS inventory, being completed either premenstrually or at midcycle, clear observable differences were shown. It is worth noting that the premenstrual profile did not describe a positive mood with, especially, elevated tension, depression and anger and low vigour; whereas Morgan's 'iceberg' was represented clearly at the midcycle stage. The contrast was most marked for the inactive group, whose profile resembled an inverted image of the midcycle shape. When subjects were allocated to groups that represented the amount of running, clear between-group differences were suggested. The lower mileage, nonamenorrhoeic runners were found to be psychologically similar to the amenorrhoeic runners premenstrually, but the former demonstrated a positive mood at midcycle. This was attributed to significantly lower tension, anger and confusion scores and, although not significant, a lower depression score $(P=0.058)$.

It was pointed out earlier that high correlations were obtained between the six mood factors at both the premenstrual and the midcycle stages. The pattern of correlations (positive correlations between tension, depression, anger, fatigue and confusion, but a negative correlation with vigour) supports the use of TMD as a summary mood disturbance indicator as exemplified in Figure 1, which shows the apparent benefit of a training programme that is intensive yet does not lead to athletic amenorrhoea. While TMD for the non-amenorrhoeic athletes was greater premenstrually than at midcycle, the premenstrual TMD score for sedentary subjects was even higher. The two POMS tests for amenorrhoeic runners present evidence of acceptable test reliability - non-significant differences between 'premenstrual' and 'midcycle' TMD scores - although this result may have been fortuitous since mood measures are susceptible to variation for reasons other than the influence of the menstrual cycle. In this instance, it appears that such effects on mood were powerful for those subjects who menstruated.

Figure 2 and Figure 3 may be less informative than Figures $4 a-c$, since they illustrate main effects only, which are inclined to mask the interaction effects illustrated in Figure 4. However, the group main effect (Figure 2) serves to illustrate that over the course of a normal cycle of approximately 28 days, exercise has a most beneficial effect upon psychological well-being. On the other hand, exercise that is of sufficient intensity to disturb normal hormonal balance among females is psychologically selfdefeating, producing a profile that is not superior to that of a group of inactive women. Similarly, Figure 3 illustrates the overall main effect of the menstrual cycle on mood for all 40 women subjects, 33 of whom had a normal menstrual cycle. The general negative effects of premenstrual mood can be seen clearly when a comparison is made with the midcycle profile.

Figure $4 a$ contains results from only seven subjects, but because the mood profiles of amenorrhoeic athletes have not, as a rule, been represented in the literature, these data provide a useful base from which to commence psychological studies of amenorrhoeic females. Figure $4 b$ depicts clearly that intensive exercise is psychologically beneficial for women. Although it is likely that premenstrual mood will be 'less good' than midcycle mood, negative symptoms are likely to be mild. It is, of course, inappropriate to claim this as a general effect across all nonamenorrhoeic women who run regularly. There will always be some for whom exercise is ineffective in alleviating the effects of premenstrual mood swings. Figure $4 c$ presents a strong case for the psychological benefits of exercise, and a next step would be to study inactive women whose individual premenstrual and midcycle profiles are similar to those represented in Figure $4 c$, and to examine the effects of an exercise programme for each subject. It might be found that while exercise has a beneficial within-group effect, there are also marked between-subject differences.

Overall, sedentary females were more tense, depressed and less vigorous than runners, confirming a positive relationship between exercise and mental health ${ }^{35-37}$. It has been documented that regular physical activity can act as a natural tranquillizer $^{38}$ and that daily exercise provides relaxation, emotional stability and serves to reduce tension ${ }^{39,40}$. Such observations should be treated with caution, however, since an interesting finding from the present study was that the amenorrhoeic runners produced a 'less-desirable' profile than either the non-amenorrhoeic runners or the inactive group. In particular, the amenorrhoeic subjects produced a high anger score. This is contrary to Morgan's general contention that anger and hostility are subdued with exercise. Here, from among the three groups, only the menstruating runners' profiles were icebergshaped. It is proposed, therefore, that although in general terms running is beneficial to health and psychological well-being, training to the extent and intensity whereby an athlete becomes amenorrhoeic can have detrimental psychological consequences. This view has been supported by Williams and Getty $^{14}$. It appears that the amenorrhoeic runners were subjected to greater stress than the other athletes and that this stress was both the cause and the outcome of athletic amenorrhoea. Highet ${ }^{2}$ has suggested recently that stress influences hypothalamic dysfunction and may even disrupt the reproductive system totally.

Gondola and Tuckman ${ }^{41}$ have suggested that there may be optimal levels of exercise that will produce the most positive mood. However, the present data suggest that mood may also be influenced more by a fundamental physiological variable, namely the incidence of athletic amenorrhoea among subjects. It was not, of course, possible to obtain premenstrual mood-state measures of amenorrhoeic runners, but when their data were placed alongside those of menstruating runners and inactive females, the amenorrhoeic runners' overall profile was quite similar to that of the inactive group. On the other hand, it was shown that running was probably a contributory factor in alleviating the negative emotional symptoms associated with PMS, with a lower 
premenstrual total mood disturbance score among menstruating runners than among inactive subjects. This observation brings into focus the suggestion by Agnew and Levin ${ }^{42}$ that depressed people are unlikely to run, rather than running being a useful vehicle for reducing depression, a view that requires a more thorough investigation.

Perhaps the most interesting finding from the present experiment was the clearly observable difference between the premenstrual and midcycle profiles for the 33 menstruating subjects. The potential benefits from regular exercise in reducing, or even eliminating, PMS ${ }^{43}$ were confirmed, while Prior et al. ${ }^{44}$ have explained that the adverse physical and psychological symptoms of PMS are reduced with athletic conditioning owing to changes in neurotransmitter levels.

In conclusion, it is suggested that given the benefits of exercise in enhancing moods, the extent and intensity of exercise merits further investigation. Also, it will be important to designate the term 'inactive' more specifically and to describe the physical characteristics of athletes more fully, for example in respect of percentage body fat. The finding that amenorrhoeic runners were not psychologically healthier than sedentary subjects was an important one and requires examination, as does the study of mood states among inactive men and men athletes by way of comparison with women. There were also differences between specific mood factors when amenorrhoeic runners were compared with non-amenorrhoeic runners. Such differences did not appear to be a reflection of exercise-induced fatigue, but rather of the incidence of athletic amenorrhoea.

\section{References}

1 Braun P. Athletic amenorrhea. Sport Health 1988; 6: 16-19.

2 Highet R. Athletic amenorrhoea - update on aetiology complications and management. Sports Med 1989; 7: 82-108.

3 Timonen S, Procope B. Premenstrual syndrome and physical exercise. Acta Obstet Gynecol Scand 1971; 50: 331-7.

4 Speroff L, Redwine DB. Exercise and menstrual function. Physician Sports Med 1980; 8: 41-2.

5 Bullen BA, Skrinar GS, Beitins IZ, von-Mering G, Turnbull BA, McArthur JW. Induction of menstrual disorders by strenuous exercise in untrained women. $N$ Engl J Med 1983; 312: 1349-53.

6 Ewing JH, Scott DG. Effects of aerobic exercise upon effect and cognition. Percept Mot Skill 1984; 59: 407-14.

7 Prior JC, Vigna Y. Conditioning exercise and premenstrual symptoms. I Reprod Med 1987; 32: 423-8.

8 Cowart VS. Can exercise help women with PMS? Physician Sports Med 1989; 17: 169-78.

9 Morgan WP, Johnson RW. Psychological characteristics of elite wrestlers: a mental health model. Paper presented at the Annual Meeting of American College of Sports Medicine, Chicago, Illinois, 1977.

10 Sachs ML, Pargman D. Running addiction: a depth interview examination. J Sport Behav 1979; 2: 143-55.

11 Dienstbier RA. Exercise, catecholamines and personality. Paper presented at the Cornell University Medical College for the Third Annual Psychology of Running Seminar, New York, 1980.

12 Thaxton L. Physiological and psychological effects of shortterm exercise addiction on habitual runners. J Sport Psychol 1982; 4: 73-80.

13 Zetner RW. Psychological effects of a running programme. Diss Abstr Int 1982; 42: 3452.
14 Williams JM, Getty D. Effect of levels of exercise on psychological mood states, physical fitness, and plasma beta-endorphin. Percept Mot Skill 1986; 63: 1099-1105.

15 Laura RS, Lee C. Amenorrhea: exercise/diet connection. Muscle and Fitness, Oct 1989: 239-40.

16 Dyer JB, Crouch JG. Effects of running and other activities on moods. Percept Mot Skill 1988; 67: 43-50.

17 Shangold $M$. Women and exercise: hormonal and endocrine effects. Exerc Sport Sci Rev 1984; 12: 53-79.

18 Carlberg KA, Buckman MT, Peake GT, Reidesel ML. A survey of menstrual function in athletes. Eur J Physiol 1983; 51: 211-22.

19 Feicht CB, Johnson TS, Martin BJ, Sparkes KE, Wagner WW. Secondary amenorrhea in athletes. Lancet 1978; 2: 1145-6.

20 Kaiserauer S, Snyder AC, Sleeper M, Zierath J. Nutritional, physiological, and menstrual status of distance runners. Med Sci Sports Exerc 1989; 21: 120-5.

21 Wakat DK, Sweeney KA, Rogol AD. Reproductive system function in women cross-country runners. Med Sci Sports Exerc 1982; 14: 263-9.

22 Boyden TW, Paneter RW, Stanforth P, Rotkins T, Wilmore $\mathrm{JH}$. Sex steroids and endurance running in women. Fertil Steril 1983; 39: 629-32

23 Linnell SL, Stager JM, Blue PW, Oyster N, Robertshaw D. Bone mineral content and menstrual regularity in female runners. Med Sci Sport Exerc 1984; 16: 343-8.

24 Glass AR, Deuster PA, Kyle SP, Yahiro JA, Vigersky RA, Schoomaker EB. Amenorrhea in Olympic marathon runners. Fertil Steril 1987; 48: 740-5.

25 Dale E, Gerlach DH, Wilhite AL. Menstrual dysfunction in distance runners. Obstet Gynecol 1979; 54: 47-53.

26 Schwartz B, Rebare RW, Yen SSC. Amenorrhea and long distance running. Fertil Steril 1980; 34: 306.

27 Ferstle J. Secondary amenorrhea linked stress. Physician Sports Med 1978; 6: 24.

28 McNair DM, Lorr M, Droppleman LF. Manual for Profile of Mood States questionnaire. San Diego California: Educational and Industrial Testing Service, 1971.

29 Morgan WP. Test of champions: the iceberg profile. Psychology Today 1980: 92-9, 101, 108.

30 Cockerill IM, Nevill AM, Lyons N. Modelling mood states in athletic performance. J Sports Sci 1991; 9: 205-12.

31 Mackenberg EJ, Brouerman DM, Vogel W, Klaiber EL. Morning-to-afternoon changes in cognitive performances and in the electroencephalogram. J Educ Psychol 1974; 66: 238-46.

32 Horne JA, Ostberg O. A self-assessment questionnaire to determine morningness-eveningness in human circadian rhythms. Int J Chronobiol 1976; 4: 97-110.

33 Thayer RE. The Biopsychology of Mood and Arousal. Oxford: Oxford University Press, 1989.

34 BMDP Statistical Software, 1440 Sepulveda Boulevard, Los Angeles, California 90025, USA, 1985.

35 Wilson VE, Morley NC, Bird EL. Mood profiles of marathon runners, joggers and non-exercisers. Percept Mot Skill 1980; 50: 117-18.

36 Berger BB, Owen DR. Mood alterations with swimming swimmers really do feel better. Psychosom Med 1983; 45: 425-33.

37 Dyer JB, Crouch JG. Effects of running on moods: a time-series study. Percept Mot Skill 1987; 64: 783-9.

38 Young RJ, Ismail AH. Personality differences of adult men before and after a physical fitness programme. Res Quart 1976; 47: $513-19$.

39 Baekeland F, Lasky R. Exercise and sleep patterns in college athletes. Percept Mot Skill 1966; 23: 1203-7.

40 Gary V, Guthrie D. The effect of jogging on physical fitness and self concept in hospitalized alcoholics. Q J Stud Alcohol 1972; 33: 1073-8.

41 Gondola JC, Tuckman BW. Extent of training and mood enchancement in women runners. Percept Mot Skill 1983; 57: 333-4.

42 Agnew R, Levin ML. The effect of running on mood and perceived health. I Sport Behav 1987; 10: 14-27.

43 Zanker C. Fit or fertile. Today's Runner December 1989: 38-41.

44 Prior JC, Vigna Y, Sciarretta D, Alojado N, Schulzer M. Conditioning exercise decreases premenstrual symptoms: a prospective, controlled six-month trial. Fertil Steril 1987; 47: 402-8. 